\title{
Glycopeptide-resistant enterococci: a decade of experience
}

\author{
NEIL WOODFORD \\ Antibiotic Reference Unit, Central Public Health Laboratory, London NW9 5HT
}

\begin{abstract}
Since their first description in 1988, glycopeptide-resistant enterococci (GRE) have emerged as a significant cause of nosocomial infections and colonisations, particularly in Europe and the USA. Two major genetically distinct forms of acquired resistance, designated VanA and VanB, are recognised, although intrinsic resistance occurs in some enterococcal species (VanC) and a third form of acquired resistance (VanD) has been reported recently. The biochemical basis of each resistance mechanism is similar; the resistant enterococci produce modified peptidoglycan precursors that show decreased binding affinity for glycopeptide antibiotics. Although VanA resistance is detected readily in the clinical laboratory, the variable levels of vancomycin resistance associated with the other phenotypes makes detection less reliable. Under-reporting of VanB resistance as a result of a lower detection rate may account, in part, for the difference in the numbers of enterococci displaying VanA and VanB resistance referred to the PHLS Laboratory of Hospital Infection. Since 1987, GRE have been referred from $>1100$ patients in almost 100 hospitals, but $88 \%$ of these isolates displayed the VanA phenotype. It is possible that, in addition to the problems of detection, there may be a real difference in the prevalence of VanA and VanB resistance reflecting different epidemiologies. Our present understanding of the genetic and biochemical basis of these acquired forms of glycopeptide resistance has been gained mainly in the last 5 years. However, these relatively new enterococcal resistances appear still to be evolving; there have now been reports of transferable VanB resistance associated with either large chromosomally borne transposons or plasmids, genetic linkage of glycopeptide resistance and genes conferring high-level resistance to aminoglycoside antibiotics, epidemic strains of glycopeptide-resistant Enterococcus faecium isolated from multiple patients in numerous hospitals, and of glycopeptide dependence (mutant enterococci that actually require these agents for growth). The gene clusters responsible for Van $A$ and VanB resistance are located on transposable elements, and both transposition and plasmid transfer have resulted in the dissemination of these resistance genes into diverse strains of several species of enterococci. Despite extensive research, knowledge of the origins of these resistances remains poor. There is little homology between the resistance genes and DNA from either intrinsically resistant gram-positive genera or from the soil bacteria that produce glycopeptides, which argues against direct transfer to enterococci from these sources. However, recent data suggest a more distant, evolutionary relationship with genes found in glycopeptide-producing bacteria. In Europe, VanA resistance occurs in enterococci isolated in the community, from sewage, animal faeces and raw meat. This reservoir suggests that VanA may not have evolved in hospitals, and its existence has been attributed, controversially, to use of the glycopeptide avoparcin as a growth promoter, especially in pigs and poultry. However, as avoparcin has never been licensed for use in the USA and, to date, VanB resistance has not been confirmed in non-human enterococci, it is clear that the epidemiology of acquired glycopeptide resistance in enterococci is complex, with many factors contributing to its evolution and global dissemination.
\end{abstract}

Received 12 Jan. 1998; accepted 28 Feb. 1998.

The 20th C. L. Oakley Lecture was given at the 176th Meeting of the Pathological Society of Great Britain and Ireland, 7 Jan. 1998. 


\section{Introduction}

On 2 Jan. 1988, The Lancet published a letter entitled 'Vancomycin-resistant enterococci' written by Anne Uttley from Dulwich PHL in collaboration with Robert George and colleagues then working in the Antibiotic Reference Unit at the Central Public Health Laboratory [1]. This was the first published report of enterococci resistant to high-levels of the glycopeptide antibiotics, vancomycin and teicoplanin. Enterococci showing similar resistance had been reported at the 1987 Interscience Conference on Antimicrobial Agents and Chemotherapy (ICAAC) [2] and this work was published on 21 July 1988 in the New England Journal of Medicine by Roland Leclercq, Patrice Courvalin and colleagues from Paris [3]. These two publications heralded the arrival in clinical microbiology of vancomycin-resistant enterococci (VRE), although it is more appropriate to refer to these bacteria as glycopeptide-resistant enterococci (GRE); the latter acronym will be used here. Recognition of GRE made clinicians and microbiologists aware that glycopeptides could no longer be relied upon to provide a last line of defence against serious infections caused by gram-positive bacteria. Since then, the lack of reliable therapeutic alternatives for serious gram-positive disease has remained a major driving force for the academic and clinical research that has been undertaken into glycopeptide resistance. In the last decade, understanding of glycopeptide resistance has increased greatly, but the clinical importance of GRE for hospital patients has been and will, no doubt, continue to be debated. Cynics argue that relatively few clinical isolates of GRE (in comparison with, e.g., isolates of methicillin-resistant Staphylococcus aureus, MRSA) have given many researchers a steady supply of publications. However, for others, GRE are a serious concern, especially when they cause life-threatening disease, such as endocarditis; indeed, multiple antibiotic resistance means that some GRE strains are 'untreatable' with almost all currently licensed agents. Hence, a detailed understanding of their epidemiology and ability to disseminate resistance, not only to other enterococci but also to other genera, may allow development of rational infection control policies. This review aims to provide an overview of knowledge of GRE and to highlight areas of current and future research.

\section{Classes of glycopeptide resistance}

Four phenotypic classes of GRE are currently recognised (Table 1) [4-11]. The first isolates of GRE were from hospital patients in 1986 and were highly resistant to vancomycin (MIC $\geqslant 256 \mathrm{mg} / \mathrm{L}$ ) and cross-resistant to teicoplanin ( $\mathrm{MIC} \geqslant 128 \mathrm{mg} / \mathrm{L}$ ). These isolates exhibited what is now known as the VanA resistance phenotype and, while most VanA enterococci continue to display high-level vancomycin resistance, the levels of resistance displayed to teicoplanin are now more varied, with many isolates showing lower levels of resistance (MIC $8-32 \mathrm{mg} / \mathrm{L}$ ). Most VanA enterococci are isolates of Enterococcus faecium, but this phenotype occurs also in E. faecalis and occasionally in E. avium, E. casseliflavus, $E$. durans, E. gallinarum and E. raffinosus [12]. This form of resistance is transferable, in association with plasmids and transposons (Table 1), so its recognition in species other than those named would not be surprising. Indeed, transfer of VanA resistance to nonenterococcal bacterial species, including $S$. aureus, has been demonstrated in vitro $[13,14]$, and VanA resistance has also been documented in occasional clinical isolates of other genera $[15,16]$.

A second class of resistance was reported at the 1987 ICAAC meeting [17] and again in 1989 [18, 19]. It was associated with low levels of vancomycin resistance (MICs of $16-64 \mathrm{mg} / \mathrm{L}$ ), but sensitivity to teicoplanin ( $\mathrm{MIC} \leqslant 4 \mathrm{mg} / \mathrm{L}$ ). This VanB phenotype is found predominantly in E. faecalis and E. faecium, but has also been observed in rare isolates of other enterococcal species, including E. casseliflavus (personal unpublished observation). It is now recognised that the MICs of vancomycin for enterococci expressing VanB resistance vary among isolates (usual range $8-1024 \mathrm{mg} / \mathrm{L}$ ), but teicoplanin sensitivity remains typical for almost all enterococci with this phenotype

Table 1. Phenotypic classes of glycopeptide resistance in enterococci

\begin{tabular}{|c|c|c|c|c|}
\hline Characteristic & VanA & VanB & VanC & VanD* \\
\hline Type of resistance & Acquired & Acquired & Intrinsic & Acquired \\
\hline Vancomycin MIC & $\geqslant 64 \mathrm{mg} / \mathrm{L}$ & $\geqslant 8 \mathrm{mg} / \mathrm{L}$ & $8-32 \mathrm{mg} / \mathrm{L}$ & $64 \mathrm{mg} / \mathrm{L}$ \\
\hline Teicoplanin $\mathrm{MIC}^{\dagger}$ & $\geqslant 8 \mathrm{mg} / \mathrm{L}$ & $\leqslant 4 \mathrm{mg} / \mathrm{L}$ & $\leqslant 4 \mathrm{mg} / \mathrm{L}$ & $4 \mathrm{mg} / \mathrm{L}$ \\
\hline Expression $^{\ddagger}$ & Inducible & Inducible & Constitutive & Constitutive \\
\hline Location of resistance genes & Plasmids or chromosome & Chromosome or plasmids & Chromosome & $?$ \\
\hline Transferable plasmids & Yes & Yes & No & No \\
\hline Transposons $\S^{\S}$ & Yes $(\operatorname{Tn} 1546)$ & Yes $(\operatorname{Tn} 1547)$ & No & $?$ \\
\hline $\begin{array}{l}\text { Terminal residues of peptidoglycan } \\
\text { precursors }\end{array}$ & D-ala-D-lac & D-ala-D-lac & D-ala-D-ser & D-ala-D-lac \\
\hline
\end{tabular}

\footnotetext{
${ }^{*}$ Characteristics of the single VanD strain of E. faecium described to date [4].

${ }^{\dagger}$ Rare VanA isolates may be teicoplanin sensitive [5] and constitutive VanB mutants [6, 7] are teicoplanin resistant

${ }^{\ddagger}$ Constitutive expression of Van A [8] and VanB [6, 7] and inducible expression of VanC [9] have been reported.

${ }^{\$}$ Only the designations of the prototype $\operatorname{VanA}[10]$ and $\operatorname{VanB}[11]$ resistance transposons are given.

$\|$ Precursors of GRE terminate in D-alanyl-D-lactate or D-alanyl-D-serine.
} 
$[6,20]$. As with VanA resistance, the VanB phenotype is a transferable trait (Table 1) and is, to date, the only form of glycopeptide resistance confirmed in a clinical isolate of the genus Streptococcus (an isolate of $S$. bovis [21]).

Whereas VanA and VanB resistance are both acquired traits, the third enterococcal glycopeptide resistance phenotype, VanC, is an intrinsic property of $E$. gallinarum and E. casseliflavus. Isolates of these two species typically display low-level resistance to vancomycin (MICs of $8-32 \mathrm{mg} / \mathrm{L}$ ), but are sensitive to teicoplanin in vitro (MICs of $\leqslant 4 \mathrm{mg} / \mathrm{L}$ ) [22]. Recently, a fourth phenotype, $\mathrm{VanD}$, has been described in a single strain of E. faecium [4]. It is distinguishable from the VanB phenotype most readily by determination of genotype (see below), although studies of the growth characteristics of the isolate in the presence and absence of glycopeptides to determine the form of resistance expression may also be appropriate (Table 1).

\section{Detecting glycopeptide resistance in enterococci}

The ability of the clinical laboratory to detect a strain of GRE accurately is an obvious requirement for all subsequent studies. However, this fundamental step remains problematic in many instances. Most laboratories test vancomycin primarily, but even isolates of the same resistance phenotype may display varying levels of vancomycin resistance (Table 1). Enterococci with the VanA phenotype are usually detected reliably $[23,24]$, but diffusion-based susceptibility tests (such as disks or Etests) and automated, rapid-turnaround systems have been shown repeatedly to give poorer rates of detection of the lower levels of vancomycin resistance associated with the other phenotypes [2326]. The use of 5- $\mu \mathrm{g}$ vancomycin disks in the UK gives increased reliability when detecting low levels of resistance, as compared with the use of $30-\mu \mathrm{g}$ disks $[23,27]$. A breakpoint method is probably the most reliable means of detecting all levels of vancomycin resistance, and a screening plate of brain heart infusion agar containing vancomycin $6 \mathrm{mg} / \mathrm{L}$ has been recommended in the USA by the National Committee for Clinical Laboratory Standards (NCCLS) since 1993 [28]. This screening method was used as a supplementary test by 11 of 32 laboratories in California, but was not used as the primary method in any [26]. Furthermore, in these 11 laboratories the method classified correctly five GRE strains (VanA, VanB and VanC phenotypes) and one glycopeptide-sensitive strain included in the same distribution.

More accurate detection and reporting of the various forms of glycopeptide resistance should be a goal for all laboratories, as it is a prerequisite for controlling the spread of resistance [26]. Hence, once vancomycin resistance is confirmed in an isolate, the laboratory should also be able to report confidently its glycopeptide resistance phenotype. A general scheme that may be used to assign these phenotypes is presented in Fig. 1. The ability to detect teicoplanin resistance (which may be difficult with diffusion-based methods if the isolate is not highly resistant) and to speciate the isolate accurately are sufficient to allow clinical laboratories to assign a phenotype with a high degree of confidence. However, isolates have been described that provide exceptions and examples of these are

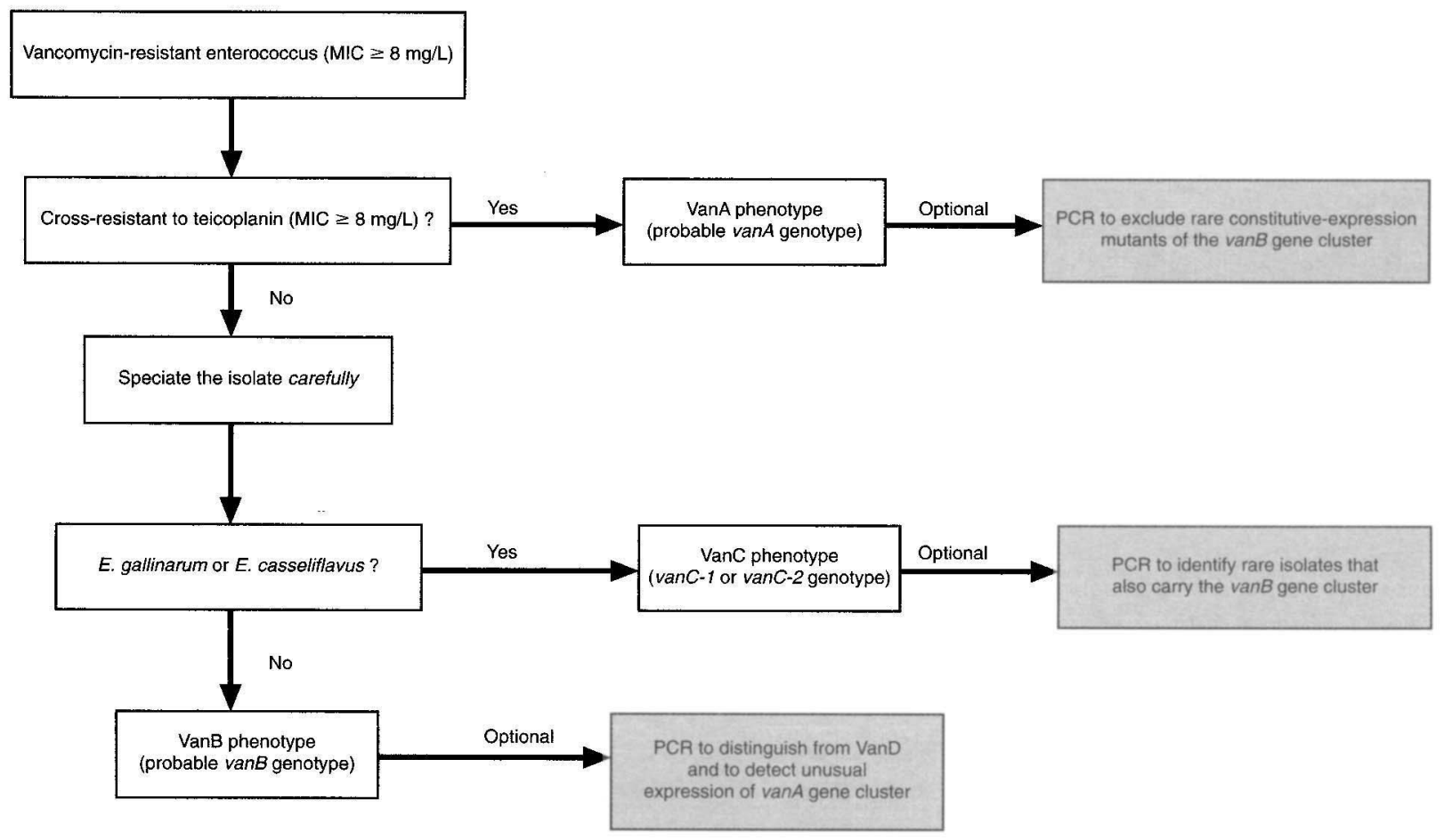

Fig. 1. Scheme for assigning a glycopeptide resistance phenotype to a vancomycin-resistant enterococcus. 
indicated (footnotes to Table 1; Fig. 1). Therefore, although still beyond the requirements of many laboratories at present, determination of the genotype of the isolate defines the type of GRE by detecting the vanA, vanB, vanC-1, vanC-2 or vanD genes (Table 2 [4, 29-34], see below). These genotypic assays are currently most cost-effective when performed in reference laboratories, in which they can be targeted at isolates that show anomalous patterns of resistance. Such assays have become possible following detailed characterisation of the genetic and biochemical basis of the various resistance phenotypes.

\section{Biochemical and genetic basis of resistance}

\section{Altered D-ala-D-ala ligases}

Although GRE may be divided into four phenotypic classes, the biochemical basis of resistance in each class is fundamentally similar. Vancomycin and teicoplanin inhibit cell-wall synthesis in gram-positive bacteria by binding to the D-alanyl-D-alanine (D-alaD-ala) groups at the termini of peptidoglycan precursors, with subsequent steric inhibition of the transpeptidation and transglycosylation reactions required to incorporate these precursors into growing peptidoglycan chains [27]. CRE produce modified peptidoglycan precursors with altered terminal groups that have decreased affinity (up to 1000-fold) either for vancomycin alone, or for both vancomycin and teicoplanin. In the acquired $\operatorname{Van} A, \operatorname{Van} B$ and $\operatorname{Van} D$ phenotypes, the precursors terminate in the depsipeptide D-alanyl-D-lactate (D-ala-D-lac) [4, 35-38], while a modified dipeptide, D-alanyl-D-serine (D-ala-D-ser), is present in the VanC phenotype [39] (Table 1).

All GRE have genes whose products have homology with bacterial D-ala-D-ala ligases, i.e., the enzymes that produce the dipeptide target of glycopeptide antibiotics. The products of these genes are ligases with altered specificities and produce either the D-ala-
D-lac depsipeptide or the D-ala-D-ser dipeptide [4, 4044]. These ligase-encoding genes are specific for the four different phenotypes and have similar designations. Thus, the vanA gene encodes the ligase associated with the VanA phenotype, and the ligases of the VanB, VanC and VanD phenotypes are encoded by the genes vanB, vanC-1 (in E. gallinarum), vanC-2 (in E. casseliflavus) and vanD, respectively. PCR can be used to distinguish these genotypes. Many such assays have been described, but for simplicity, the reader is referred to the two multiplex assays with which the author has most experience (Table 2; assays I and III) [29-34], together with an assay for the newly described vanD gene (Table 2; assay II) [4].

\section{Location of the ligase genes}

The genetic bases of the VanA and VanB resistance phenotypes have been characterised most fully. In both cases, the ligase-encoding vanA and vanB genes form part of complex gene clusters. In the prototype VanA and VanB strains, these gene clusters are located on large transposable elements (Fig. 2); Tn1546 (vanA gene cluster) is a $10.8-\mathrm{kb} \mathrm{Tn} 3$-related transposon [10], while Tn 1547 (vanB gene cluster) is a 64-kb composite transposon flanked by IS256-like and IS 16 elements [11]. It is generally assumed that the dissemination of VanA and VanB glycopeptide resistance to diverse strains of various enterococcal species has been made possible by the existence of these transposable elements and also by their frequent association with transmissible plasmids. VanA resistance appears usually to be plasmid-mediated $[3,45]$, although chromosomally located vanA genes have been reported [46]; resistance is often transferable from both locations. Although originally thought to be non-transferable [18, 19], the genes associated with VanB resistance can also be transferred in association with large chromosomally borne transposons $[6,11,47]$ or, less frequently, with self-transmissible plasmids $[29,30]$. The intrinsic vanC-1 and vanC-2 genes of E. gallinarum and $E$.

Table 2. Primers suitable for determining the van genotype and species of GRE

\begin{tabular}{|c|c|c|c|}
\hline Assay (reference) & Gene & PCR primers $\left(5^{\prime}-3^{\prime}\right)^{*}$ & Product size (bp) \\
\hline I $[29-31]$ & $\begin{array}{l}\text { van } A \\
\text { van } B\end{array}$ & $\begin{array}{l}\text { F-ATGGCAAGTCAGGTGAAGATGG } \\
\text { R-TCCACCTCGCCAACAACTAACG } \\
\text { F-TCTGTTGAATTGTCTGGTAT } \\
\text { R-GACCTCGTTTAGAACGATG }\end{array}$ & $\begin{array}{l}399 \\
589\end{array}$ \\
\hline II [4] & $\operatorname{van} D$ & $\begin{array}{l}\text { F-TAAGGCGCTTGCATATACCG } \\
\text { R-TGCAGCCAAGTATCCGGTAA }\end{array}$ & 461 \\
\hline III $[32-34]^{\dagger}$ & $\begin{array}{l}\text { vanC-1 (E. gallinarum) } \\
\text { vanC-2 (E. casseliflavus) }{ }_{d d l_{E \text { faecalis }}{ }^{\ddagger}} \\
\text { ddl }_{\text {E.faecium }}{ }^{\ddagger}\end{array}$ & $\begin{array}{l}\text { F-GGTATCAAGGAAACCTC } \\
\text { R-CTTCCGCCATCATAGCT } \\
\text { F-CTCCTACGATTCTCTTG } \\
\text { R-CGAGCAAGACCTTTAAG } \\
\text { F-ATCAAGTACAGTTAGTCTT } \\
\text { R-ACGATTCAAAGCTAACTG } \\
\text { F-GCAAGGCTTCTTAGAGA } \\
\text { R-CATCGTGTAAGCTAACTTC }\end{array}$ & $\begin{array}{l}822 \\
439 \\
941 \\
550\end{array}$ \\
\hline
\end{tabular}

\footnotetext{
${ }^{*} \mathrm{~F}$ and $\mathrm{R}$ indicate forward and reverse primers, respectively.

TPrimer pairs in this assay may be used to assign the isolate to one of the four indicated species

*The genes $d d l_{E . f a e c a l i s}$ and $d d l_{E \text { faecium }}$ encode the native D-ala-D-ala ligases of $E$. faecalis and E. faecium, respectively.
} 
a)

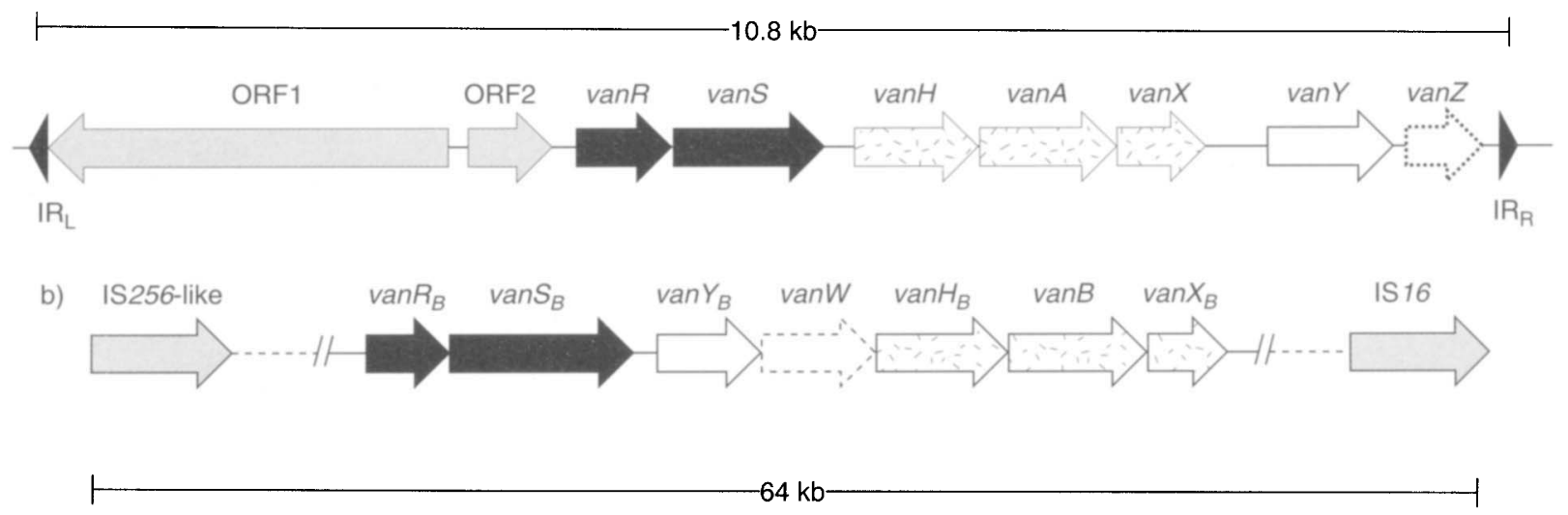

Fig. 2. Structure of (a) VanA transposon $\operatorname{Tn} 1546$ and (b) VanB transposon $\operatorname{Tn} 1547$. The various shades indicate genes with similar functions between the two elements.

casseliflavus are located on the chromosome and are not transferable. The location of the vanD ligase gene has not been reported yet [4] although, by analogy with VanA and VanB resistance, VanD enterococci with plasmid-mediated and chromosomal genes would be anticipated.

\section{$A$ requirement for multiple gene products}

In contrast to mechanisms that confer resistance to most other classes of antimicrobials, glycopeptide resistance does not depend solely on the product of one gene. Although the ligase-encoding genes are necessary to produce the altered peptidoglycan precursors, they are not sufficient to confer phenotypic glycopeptide resistance upon a cell. Expression of resistance depends on the presence of two further essential genes, designated $v a n H$ and $\operatorname{van} X$ (in VanA strains) or $v_{a n} H_{B}$ and $\operatorname{van}_{B}$ (in VanB strains). The vanH/vanH $H_{B}$ genes encode enzymes that convert pyruvate to D-lactate [48-50] and so make this molecule available to the vanA- and vanB-encoded ligases. As VanA and VanB are acquired resistances, the pathway for producing glycopeptide-resistant peptidoglycan precursors is additional to the native chromosomally encoded, glycopeptide-sensitive path. This chromosomal pathway appears not to be switched off when resistance is expressed, and so sensitive precursors terminating in D-ala-D-ala are still produced. The products of the $\operatorname{van} X / \operatorname{van}_{B}$ genes are dipeptidases and are essential for cleaving the D-ala-D-ala dipeptide to prevent its incorporation into precursors $[50,51]$.

In addition to the van $H A X$ genes, the VanA transposon Tn 1546 also has two other accessory, but non-essential van genes located downstream of the essential region (Fig. 2) [10, 27]; van $Y$ encodes a penicillin-insensitive carboxypeptidase $[52,53]$ and $\operatorname{van} Z$ encodes an uncharacterised product that confers low-level teicoplanin resistance [54]. The VanB element Tn1547 also encodes a carboxypeptidase (the product of the $\operatorname{van} Y_{B}$ gene) and carries a gene (van W) with no homologue in the vanA cluster; the product of van $W$ has unknown function [50]. However, on Tn1547, van $Y_{B}$ and vanW are both located between the regulatory genes (see below) and the $v_{a n} H_{B} \mathrm{BX}_{B}$ essential genes (Fig. 2) [50]. The position of these two genes upstream of the essential genes suggests that they may play a more significant role in the expression of VanB resistance than that played by van $Y$ and $\operatorname{van} Z$ in VanA resistance.

\section{Regulation of resistance}

One of the first observations made regarding VanA and VanB enterococci was that their resistance was inducible in the presence of glycopeptides [18, 55, 56]. Considering only those glycopeptides available for clinical use, VanA resistance is induced by exposure to vancomycin or teicoplanin, whereas $\operatorname{VanB}$ resistance is induced only following exposure to vancomycin. It is now understood that the two resistance gene clusters both include genes that encode a two-component regulatory system $[50,57]$.

The products of the vanS (in VanA strains) and $v a n S_{B}$ (in VanB strains) genes are transmembrane peptides that sense environmental glycopeptides and autophosphorylate in response to their presence [50, 57]. Phosphoryl groups are rapidly transferred from the sensors to the products of the $v a n R$ or $v a n R_{B}$ genes and, in their phosphorylated forms (phospho-VanR or phospho-Van $R_{B}$ ), these proteins bind to specific promoter sites within the vanA [58] and $\operatorname{van} B$ [50] gene clusters. Transcription of the essential resistance genes then occurs [27]. In the absence of a glycopeptide stimulus, VanS dephosphorylates phospho-VanR and thereby switches off expression of VanA resistance [59]. Absence of such a negative regulator should therefore not affect expression of resistance adversely and indeed, insertional inactivation of vanS has confirmed that the sensor protein is not essential for a VanA phenotype [57], although resistance is expressed constitutively in such mutants, rather than inducibly [59]. Conversely, the VanR protein is essential, as inactivation of the corresponding gene restores glycopeptide sensitivity $[57,60]$. $\operatorname{Van} \mathrm{S}_{\mathrm{B}}$ may have a similar negative regulatory 
role for VanB resistance, but this has not been investigated. In contrast to VanS, the $\operatorname{VanS}_{\mathrm{B}}$ protein does not normally recognise environmental teicoplanin, which explains the inability of this glycopeptide to induce VanB resistance [50], although point mutations have been identified in the $\mathrm{N}$-terminal domain of the $\mathrm{VanS}_{\mathrm{B}}$ protein that do permit induction of resistance by teicoplanin [61].

\section{Glycopeptide dependence}

Variants of VanA or VanB enterococci have been described that actually require glycopeptides for growth. These have been isolated from clinical material [62-67] and following exposure of GRE to glycopeptides in vitro $[68,69]$. The presence of two pathways for the synthesis of peptidoglycan precursors in GRE led to the suggestion that dependent strains had defective D-ala-D-ala ligases and were unable to synthesise normal peptidoglycan. However, in the presence of a glycopeptide, the alternative pathway (D-ala-D-lac) is induced, allowing peptidoglycan synthesis and cell growth [27]. This hypothesis has been confirmed for two isolates $[61,70]$. The clinical relevance of dependent strains has been debated and they have been described as 'superbugs' [71]. However, in the author's opinion, they are defective GRE and should cause no more concern than GRE, except that they may not be detected by standard culture techniques $[63,66,67]$.

\section{The epidemiology of GRE in hospitals}

Although studies of the pathogenicity of enterococci are not numerous [72, 73], with $E$. faecium rarely included, GRE appear to be no more virulent than glycopeptide-sensitive strains. Moreover, many patients have been colonised, rather than infected. Furthermore, the patients affected frequently have serious underlying disease, and so a poor outcome cannot always be attributed directly to the presence of GRE.

\section{The UK situation}

In the UK, no central data are collected on the number of cases of infection with GRE, although national epidemiological data are compiled by the Public Health Laboratory Service from isolates submitted voluntarily by hospitals in England and Wales. From the first report of such bacteria [1] to Aug. 1996, the PHLS Laboratory of Hospital Infection had received GRE with acquired resistance (either the VanA or VanB phenotypes) isolated from $>1100$ individual patients in 93 UK hospitals, most (75\%) of which were isolates of E. faecium with the VanA resistance type [12]. Enterococci with the VanB phenotype accounted for only $12.5 \%$ of referred isolates. The hospitals affected by GRE ranged from large teaching hospitals to district general hospitals and, although the majority referred only sporadic isolates, outbreaks have been investigated at 25 hospitals. The foci of these outbreaks were on specialised units, such as the renal, haematological, intensive care and liver units, but strains have also spread to other units. Multi-resistant GRE have become endemic in several hospitals.

Five epidemic vancomycin (glycopeptide)-resistant strains of $\boldsymbol{E}$. faecium (EVREM) have been defined on the basis of (i) the macrorestriction digestion patterns of their genomic DNA following separation by pulsed-field gel electrophoresis (PFGE), and (ii) by isolation from at least two patients in at least two hospitals [74]. At present, the strain designated EVREM-3 is causing greatest concern. It is usually multi-resistant, with the VanA phenotype and additional high-level resistance to aminoglycosides, penicillins and numerous other antibiotic classes. It can spread rapidly within a unit and, up to Aug. 1996, had been isolated at 16 hospitals, mostly in the London area. The appearance of EVREM-3 in one hospital outside London could be attributed to the transfer of two patients from a London teaching hospital known to have the strain [75]. The recognition of strains, such as EVREM-3, lends weight to the suggestion that some strains of enterococci (including GRE) 'have heightened capabilities to colonise, overgrow, invade host tissues and persist compared with endogenous enterococcal flora' [72].

With the exception of the EVREM strains, analysis by PFGE of the GRE isolated from patients at different UK hospitals reveals marked heterogeneity. Sporadic isolates tend to have unique banding patterns and, although each hospital with a cluster of cases may have a predominant strain, the predominant strains from different hospitals are usually distinct. Given the distribution of affected hospitals throughout the UK [12], these data suggest that most GRE have emerged independently at a number of different centres, rather than simply spreading between centres. Furthermore, the wide distribution of the VanA and VanB resistance phenotypes, both of which have been associated with outbreaks [30, 45, 76], argues that these two genetically distinct, complex resistance mechanisms have arisen in multiple strains in this country. Even though the resistance genes may be transferable, the available data based on the analysis of nosocomial GRE do not provide an easy explanation for these observations and suggest that the true epidemiology of GRE is complex and includes stages outside of the hospital environment. It is this aspect of GRE that is receiving a great deal of attention at present (see below).

\section{A global perspective}

Much of the experience gained with GRE in the UK is similar to that reported from other countries. Enterococci with the VanA and VanB resistance phenotypes have been reported from many European countries and 
from the USA $[27,77]$. However, as with the UK, few other countries have published national figures for numbers of GRE infections. In a recent review of the global impact of GRE [78], McDonald and Jarvis noted that these bacteria were reported in an increasing number of countries. During 1996, GRE had been reported for the first time from Sweden and Australia, while the first hospital outbreaks had occurred in Germany, Italy and Canada. GRE have become a major infection control problem in the USA, where 'the percentage of States with a National Nosocomial Infections Surveillance system hospital reporting more than one [GRE] increased from eight $(27 \%)$ of 30 in $1989-1993$ to 16 (44\%) of 36 in 1994-1995'. Furthermore, the percentage of nosocomial enterococci resistant to vancomycin in surveillance system hospitals increased from $<0.5 \%$ in 1989 to just over $10 \%$ in 1995 [78]. As with the UK EVREM strains, instances of inter-hospital spread of GRE have been reported in the USA $[79,80]$.

\section{An environmental reservoir of GRE}

A possible explanation for the distribution of GRE among diverse hospitals in the UK is that these bacteria are endemic in the community and are selected when people are exposed to the various pressures exerted in the hospital environment. The first indication that VanA GRE could be found outside of the hospital environment was published in 1993 by Bates et al. [81] and this aspect has become a major area of research.

\section{Are we what we eat?}

In several countries in Europe, VanA enterococci have been isolated in the community and from sewage, the faeces of farm animals, and raw meat for human consumption purchased at retail outlets [82-92]. To date, recovery from these sources has not been reported in the USA [93], although a VanA enterococcus was isolated from a sample of dry dog food [94]. Hence, in Europe at least, these sources are a potential reservoir of GRE that may pass to man and affect public health. Once ingested, these strains may either colonise the human gut, or they may pass transiently, during which time their resistance genes may be passed to the endogenous enterococcal flora.

Obviously it has not been possible to investigate the ability of animal or environmental strains of GRE to colonise man or to transfer resistance genes in vivo, although there is evidence to suggest that this is a likely scenario. In a Belgian study, Van der Auwera et al. failed to isolate GRE from 22 healthy volunteers before oral administration of glycopeptides, although VanA enterococci (confirmed to contain Tn1546) were isolated from 14 of these volunteers after exposure to glycopeptide antibiotics [91]. This suggests that GRE may be present in low numbers in the guts of non- hospitalised subjects, and that these reach detectable frequencies following glycopeptide treatment. A second observation consistent with the possibility that gut carriage of GRE in man may follow exposure to an environmental reservoir is provided by the isolation of GRE from the stools of people who eat meat, but not from those of strict vegetarians [95]. The isolation of VanA enterococci from pet cats and dogs $[90,96]$ probably indicates that these species are also subject to colonisation by enterococci following ingestion of contaminated food [94].

\section{Van $A$ resistance and the association with use of avoparcin}

The existence of this environmental reservoir suggests that VanA resistance may not have evolved in hospitals and, controversially, its evolution has been attributed to the use of avoparcin [97, 98]. This glycopeptide has been used in Europe since 1975 as a growth promoter for meat production, especially in pigs and poultry [87]. VanA enterococci are cross-resistant to avoparcin, and the isolation of these bacteria from farm animals has been correlated with farms that used this agent for growth promotion purposes $[84,85,99]$. The potential risk, rather than the proven hazard, posed to public health by the continued use of avoparcin has resulted in the withdrawal of this agent pending a thorough reevaluation of its use.

A reservoir of VanA resistance genes may continue to exist in animal enterococci, despite the current suspension of avoparcin use. Although this suspension makes sense scientifically, and may decrease the direct selective pressure for VanA resistance, the economic pressures faced by the meat production industry will ensure that alternative growth promoting agents will be used in many countries. These alternatives will continue to select for GRE indirectly if the genes that confer resistance to them are linked to glycopeptide resistance genes. In this scenario, the latter genes will persist in the population and the potential remains for transmission to enterococci in man.

Avoparcin has never been licensed for use in the USA [100], which suggests that the current problems with GRE in that country may result from the clinical (over)use of vancomycin; teicoplanin is not available in the USA. However, the relative importance of the clinical use of vancomycin and teicoplanin versus the use of avoparcin for animal growth promotion as factors promoting the evolution, selection and dissemination of glycopeptide resistance and GRE in Europe requires further study.

\section{Relatedness of nosocomial versus non-hospital GRE}

Molecular typing studies are necessary to determine the relatedness of VanA GRE from human and non- 
human sources. Such studies will establish whether exchange of strains occurs, whether some strains are specific either to man or to animals, and whether the strains found in food are also present in the community and hospital patients. Some studies to investigate this have already been undertaken. GRE from different hospitals usually have distinct PFGE patterns as, indeed, may GRE isolated from patients in adjacent beds. Therefore, it is not particularly surprising that there is currently little conclusive evidence for the occurrence of strains common to man and other souces. Bates et al. [82] reported that the GRE isolated from two hospital patients and a pig had similar ribotypes, as did two isolates from the stool of a community patient and from sewage. Klare et al. [85] observed similar PFGE patterns in pairs of GRE isolated from (i) minced meat and an outpatient stool, and (ii) minced meat and a clinical specimen, while van Belkum et al. found a particular genotype of GRE in dogs, cats and a human carrier [96]. Recently, identical isolates of GRE have been obtained from turkeys and from the farmer [101], which suggests that the unrelatedness noted between most isolates in earlier studies may have been because of the lack of a sufficiently close epidemiological relationship between the isolates studied.

As only limited instances of similarity have been noted between the strains of GRE isolated from hospital patients and those isolated from other sources, it seems likely that transfer of plasmids or transposons between enterococci plays a significant role in the dissemination of VanA resistance. Hence, several groups are currently investigating the relationships between genetic elements that confer VanA resistance in enterococci isolated from man and other sources.

\section{Structure of VanA resistance elements}

Detection of the vanA gene in GRE from non-human sources (see above) implies the presence of the essential vanH and vanX genes and it has been assumed that these genes are located on elements comparable with Tn1546 [10]. In the study by Van den Auwera et al. [91], 35 VanA enterococci were shown to have gene arrangements indistinguishable from that of the prototype VanA transposon. However, restriction fragment length polymorphisms (RFLPs) occur in VanA elements [102] and appear to result from a variety of insertion sequences (IS elements) that have been found at various positions within Tn1546-like elements. Specifically, IS elements have been found at the $5^{\prime}$ end of Tn1546 (an IS $1216 \mathrm{~V} /$ truncated-IS3 complex) [46, 103] (personal unpublished observations), in the intergenic regions between the $\operatorname{orf} 2 / \mathrm{vanR}$ (IS1542) [104], vanS/vanH (IS1251) [103, 105], and vanX/vanY (IS1216V) [59] (personal unpublished observations) genes, and within the reading frames of vanY (IS1476) [106], orf1 (IS3) (personal unpublished observations) or orf2 (IS $1216 \mathrm{~V}$ ) (personal unpublished observations).

The author has recently described 24 groups of VanA resistance elements in GRE from UK hospital patients and other sources [104]. Six of these groups were found in GRE from both man and other sources, 10 groups from hospital patients only, and eight groups only from non-human sources. The groups were defined by amplifying 10 overlapping fragments of Tn1546-like elements with primers described by Arthur et al. [10], and the differences between them have been confirmed by long-PCR RFLP analysis $[107,108]$. Most of these VanA elements ranged in size from 8 to $>15 \mathrm{~kb}$, but all have intact vanRSHAX genes, indicating that all of the variation lies upstream of $\operatorname{vanR}$ or downstream of $\operatorname{vanX}$, i.e., in areas not essential for a VanA phenotype (personal unpublished observations). Twenty-one VanA groups have upstream alterations in the region associated with transposition of Tn1546 (orfl and orf2) that may affect their ability to disseminate resistance [104]. Nineteen groups have downstream alterations [104], including seven groups that lack van $Y$ and one group that lacks both van $Y$ and vanZ (personal unpublished observations). Although these two genes are not essential for the expression of VanA resistance (see above), the absence of van $Y$ from clinical isolates of VanA enterococci has not been reported previously and only one strain has been described that lacks vanZ [101].

Of particular interest was the observation that elements indistinguishable from Tn1546 were more common in enterococci from non-human sources than in strains from hospital patients. This may indicate that VanA elements become more diverse when they enter 'human' enterococci and are subjected to hospital selection pressures. Indeed, variation from $\operatorname{Tn} 1546$ is even apparent among the VanA elements of the 'original' GRE isolated from man in the late $1980 \mathrm{~s}$; some isolates from the hospital cluster reported by Uttley et al. [1, 45] contain elements indistinguishable from Tn1546, but others contain Tn1546-like elements that have alterations in orfl and IS elements in the vanX-vanY intergenic region (personal unpublished observations). Variation from $\operatorname{Tn} 1546$ was also noted in some French isolates at the time Tn1546 was characterised [10].

Recently, Jensen et al. identified a single base change (from $\mathrm{G}$ to $\mathrm{T}$ ) at position 8234 in the $\operatorname{van} X$ gene of some VanA enterococci [103]; this was the only variation from the published sequence of $\operatorname{Tn} 1546$ observed when sequencing fragments of the vanR, vanA and vanX genes [103]. In isolates studied to date, the presence of this mutation appears to correlate with VanA elements defined as 'group D' by Woodford et al. [104] and seems to be associated with GRE isolated from pig faeces and some hospital patients, but not with GRE from the faeces of other 
animals [103, 104] (personal unpublished observations).

Investigations of the structure of VanA resistance elements are providing tools for dissecting the fine details of VanA epidemiology. The various groups defined may be useful for evolutionary or snapshot epidemiological studies of this resistance. However, their value for long-term epidemiological studies will be compromised if they prove to be highly unstable; transposition of an IS element into, out of, or to a different position within a VanA element would cause the element to be assigned to a different group. Isolates of a single epidemic strain of $\operatorname{Van} A E$. faecium (EVREM-3) may have VanA elements of distinct groups [104], which suggests that VanA elements may change more rapidly than more frequently used molecular markers, such as the distribution of SmaI target sites (for PFGE) or $r r n$ operons (for ribotyping). Hence, the stability of the groups requires evaluation.

\section{Does VanB resistance occur outside hospitals?}

Although GRE with VanB resistance are not always detected readily (see above), there is a very marked difference in the proportions of VanA $(87.5 \%)$ and VanB (12.5\%) GRE referred from UK hospital patients to the PHLS Laboratory of Hospital Infection since 1987 [12]. It is possible that, in addition to the problems of detection, there may also be a real difference in the prevalence of VanA and VanB resistance that reflects different epidemiologies. Despite numerous investigations of the occurrence of GRE in the community and non-human sources, the presence of VanB enterococci in sources outside of the hospital environment remains to be proven; isolates reported to date have had the VanA or VanC phenotypes. This apparent absence of VanB resistance is puzzling. However, if real, the existence of an environmental reservoir of enterococci with the VanA resistance genes, but no similar reservoir of VanB enterococci, might contribute significantly to the different isolation rates observed from hospital patients. The clinical use of teicoplanin, which induces VanA but not VanB resistance, may play a role in the selection of resistance in hospitals.

\section{An environmental origin for glycopeptide resistance genes?}

Vancomycin and teicoplanin are both produced by soil-living bacteria (Amycolatopsis orientalis and Actinoplanes teichomyceticus, respectively) [77] and, not surprisingly, these bacteria are resistant to the action of the agents they produce. In 1990, shortly after the vanA gene was characterised [109], it was demonstrated that a probe specific for this gene failed to hybridise with DNA from either of the above species [110]. Furthermore, database searches with the nucleotide and amino-acid sequences of a teicoplanin resistance gene from $A$. teichomyceticus failed to indicate homology with known enterococcal glycopeptide resistance genes [111]. Caution has been urged regarding over-interpretation of negative hybridisation data [110], but the apparent sequence divergence reported between the resistance genes of enterococci and that of the producer of teicoplanin [111] suggests that recent acquisition of VanA resistance by enterococci from glycopeptide-producing species is unlikely. As the sequences of the vanB and vanC genes had not then been published, comparison with these mechanisms was not undertaken.

A VanA-like phenotype of glycopeptide resistance (i.e., resistance to both vancomycin and teicoplanin) is an intrinsic characteristic of many lactobacilli, Leuconostoc spp. and Pediococcus spp. [27, 77], and results from the production of peptidoglycan precursors that terminate in D-ala-D-lac [112-114]. However, this similarity with the acquired forms of enterococcal resistance appears to be an example of convergent evolution, as there is little relationship between the various ligases involved [115].

Several major advances in our understanding of glycopeptide resistance followed the development of degenerate PCR primers suitable for amplifying $c$. 600 -bp intragenic fragments of genes (designated $d d l$ ) likely to encode enzymes related to D-ala-D-ala ligases $[43,108]$. These primers have recently been modified and used to re-evaluate the possible relationship between the genes present in glycopeptide-producing species and those of GRE [116]. Two actinomycetes were studied: A. orientalis (which produces vancomycin) and Streptomyces toyocaensis (which produces an aglycopeptide). The GC contents of the $d d l$ genes obtained from both species $(65 \%$ and $58 \%$, respectively) differed significantly from those of the vanA $(45 \%)$ or $\operatorname{vanB}(48 \%)$ genes [116]. This observation may explain the negative hybridisation results noted previously [110] and is consistent with the proposal that there has been no recent direct transfer to enterococci. However, a more distant, evolutionary relationship with the VanA and VanB resistance mechanisms, possibly involving intermediate bacterial genera, has been suggested by comparison of the amino acid sequences of the ligases. Such analysis indicates that enterococcal glycopeptide-resistant ligases are related more closely to the ligases of glycopeptide producers than they are to the ligases of intrinsically resistant genera (Fig. 3) [116]. The recent cloning of genes that encode homologues of the VanH and VanX proteins from glycopeptide-producing bacteria provides further evidence for a distant role of these species in the origin of enterococcal glycopeptide resistance (G. D. Wright, personal communication). 

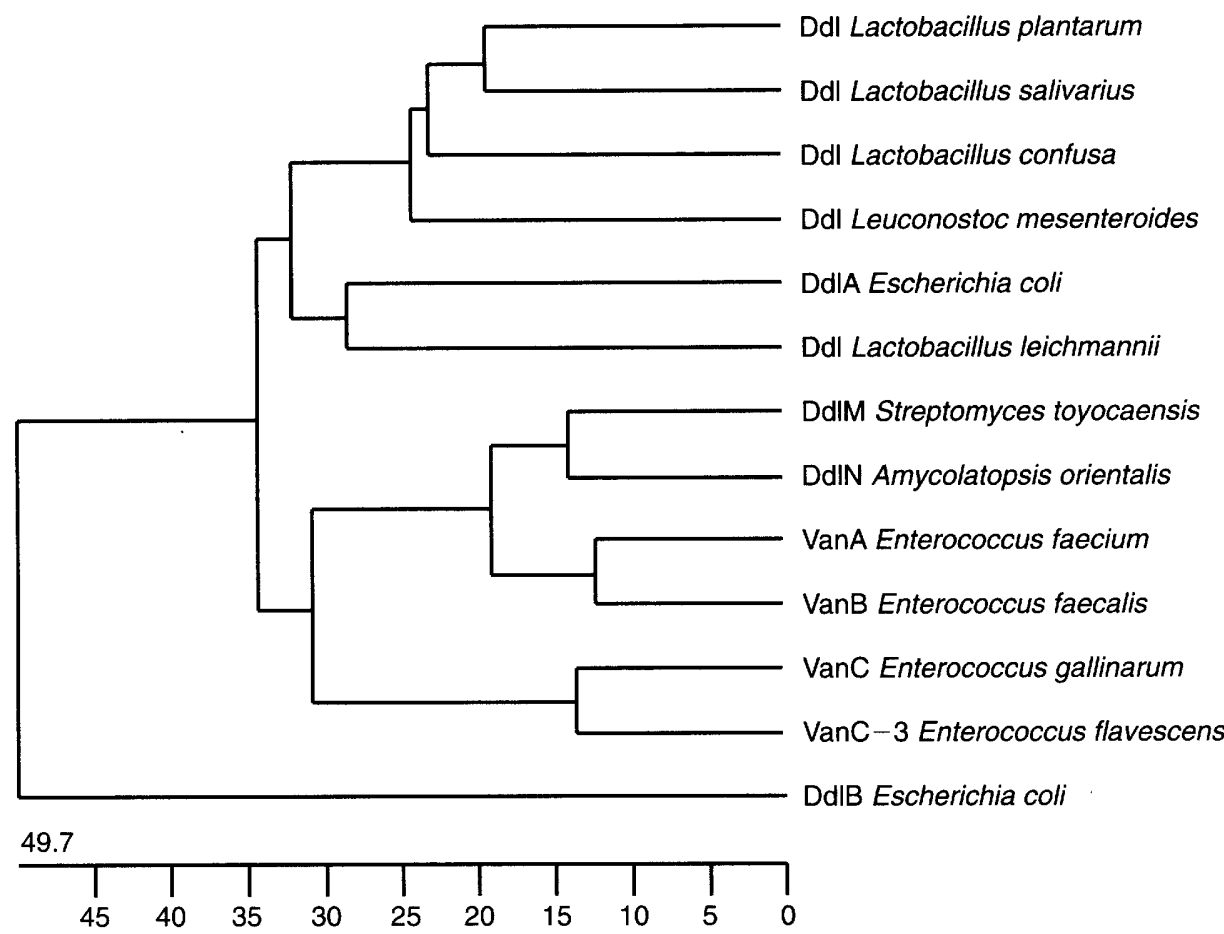

Fig. 3. Phylogenetic relationship among $d d l$ genes. The horizontal axis is the percentage distance between sequences. Reproduced from reference [116] with the permission of the authors and publisher (Copyright (1997) National Academy of Sciences, USA).

\section{Treatment of infections caused by GRE; present and future options}

Clinically, the major problem associated with multiresistant enterococci is the lack of available antibiotics with guaranteed bactericidal activity. The array of intrinsic resistance to different antibiotic classes exhibited by enterococci, their relative insensitivity to quinolones, together with their usual tolerance of the bactericidal action of penicillins and glycopeptides $[117,118]$, means that no single agent shows good activity, even against glycopeptide-sensitive members of this genus. Typically, a cell wall-active agent, such as a penicillin or glycopeptide, is used in combination with an aminoglycoside to exert synergic bactericidal anti-enterococcal activity. However, resistance to either component of the combination results effectively in non-bactericidal monotherapy, which is unsuitable for serious infections such as endocarditis and, possibly, bacteraemia [27].

As mentioned previously, many GRE isolated in the UK also exhibit high-level resistance to penicillins (strains of E. faecium) and aminoglycosides, particularly those of the VanA phenotype. Thus, should they cause serious disease, these isolates are completely resistant to proven clinical options for therapy and require the use of less-favoured therapies. Therefore, there is a need for new antimicrobial agents with activity against enterococci, including VanA GRE and multiresistant strains. For GRE of the VanB phenotype, teicoplanin plus an aminoglycoside has been suggested as a currently available bactericidal option
[119], and this regimen could probably also be considered for VanC and VanD enterococci as it has proved effective against VanB [69] and VanC [120] enterococci in animal models of endocarditis. However, clinicians should be aware that exposure of VanB enterococci to teicoplanin carries a risk of the emergence of teicoplanin-resistant mutants that express resistance constitutively $[7,69]$. Although this risk was reduced in an animal model by combination with an aminoglycoside [69], and so may not be realised clinically, patients treated with this regimen should be monitored carefully.

Several new antimicrobials are in development, including new fluoroquinolones, semi-synthetic vancomycin derivatives, glycylcyclines and oxazolinidones, and many of these exhibit good in-vitro activity against enterococci, including VanA GRE and other multiresistant strains. The reader is referred to a recent review of these agents [121].

Currently, there is considerable interest in the injectable streptogramin combination of quinupristin with dalfopristin (Synercid ${ }^{\mathrm{TM}}$ ), which may be licensed for use in the near future. Although isolates of $E$. faecalis are inherently resistant, this mixture shows good bacteristatic activity against many multiresistant strains of E. faecium. However, concern has been raised that resistance may spread fairly rapidly after the introduction of this agent into clinical use. Transferable resistance to quinupristin with dalfopristin has been reported already in strains of glycopeptide-resistant (VanA phenotype) E. faecium isolated 
from raw chicken and from hospital patients in the UK [122]. There have been similar observations of streptogramin A-resistant strains of $E$. faecium in Denmark (A. Hammerum, personal communication) and Germany (W. Witte, personal communication). As streptogramins are not used clinically in the UK, the existence of these resistant enterococci in the UK cannot be blamed upon clinical overuse or misuse of antibiotics. It seems likely that use of the related streptogramin, virginiamycin, as an animal feed additive may already have selected a reservoir of resistance genes and resistant strains of $E$. faecium. So, it looks as if the 'antibiotics in animal feed' story may be set to begin a new chapter.

\section{The future - glycopeptide-resistant MRSA?}

Resistance to vancomycin or teicoplanin, or both, has been reported in coagulase-negative staphylococci for several years and teicoplanin-resistant $S$. aureus have also been described [27, 77]. However, confirmed reports of clinical isolates of MRSA resistant to vancomycin have only appeared recently [123, 124]. These isolates, from Japan and the USA, exhibit lowlevel vancomycin resistance (MIC of $8 \mathrm{mg} / \mathrm{L}$ ) which was not detected readily by disk tests [125]. None of the glycopeptide-resistant staphylococci reported to date contains enterococcal glycopeptide resistance genes, and resistance seems unlikely to involve production of altered peptidoglycan precursors [123, 126].

Many authors have indicated the potential for the $v a n A$ or $v a n B$ gene clusters to emerge in $S$. aureus, and evidence for this possibility is provided by (i) the number of resistance genes shared by these two genera and, more directly, by (ii) the transfer of VanA resistance to a laboratory strain of methicillin-sensitive $S$. aureus [14]. Interestingly, E. faecalis strain NCTC 12201, which was used as the donor in the experiments by Noble et al. [14], contains a VanA element indistinguishable from Tn1546 (personal unpublished observations). Such elements were present in $<10 \%$ of VanA enterococci from UK hospital patients [104]. It is possible that the more common VanA elements, many of which have alterations in genes associated with transposition [104], are able to transfer less readily to other genera than $\operatorname{Tn} 1546$ itself. This may explain why VanA resistance has not yet been detected in $S$. aureus in vivo. A more detailed understanding of the factors affecting transfer of enterococcal glycopeptide determinants is needed to understand and try to avoid the conditions in which transfer to $S$. aureus is most likely to occur.

\section{Conclusions}

Many aspects of the epidemiology of GRE remain unanswered and must be understood if we are to develop rational approaches towards their control. The epidemiology of acquired glycopeptide resistance in enterococci is a complex issue and many factors have contributed to its evolution and dissemination. It seems likely that the next 2-3 years will see major developments in this area as more molecular tools, including DNA sequencing, are applied to large numbers of isolates from diverse sources and hospital clusters. Further insights are likely to be gained into the origins of the various forms of acquired resistance, but it remains to be seen whether these resistances will emerge eventually in $S$. aureus.

I am grateful to Paul Chadwick, David Livermore, Donald Morrison, Marie-France Palepou and Patricia Woodford for their helpful comments on this manuscript.

\section{References}

1. Uttley AHC, Collins $\mathrm{CH}$, Naidoo J, George RC. Vancomycinresistant enterococci. Lancet 1988; 1: 57-58.

2. Leclercq R, Derlot E, Duval J, Courvalin P. Strains of Enterococcus faecium highly resistant to vancomycin and teicoplanin. Program and Abstracts of the 27th Interscience Conference on Antimicrobial Agents and Chemotherapy 1987; 275. Abstract 1023.

3. Leclercq R, Derlot E, Duval J, Courvalin P. Plasmid-mediated resistance to vancomycin and teicoplanin in Enterococcus faecium. $N$ Engl J Med 1988; 319: 157-161.

4. Perichon B, Reynolds P, Courvalin P. VanD-type glycopeptideresistant Enterococcus faecium BM4339. Antimicrob Agents Chemother 1997; 41: 2016-2018.

5. Clark NC, Hill BC, Tenover FC. Characterization of an Enterococcus raffinosus isolate with a VanB phenotype and vanA genotype. Program and Abstracts of the 94th ASM General Meeting 1994; A-111.

6. Hayden MK, Picken RN, Sahm DF. Heterogeneous expression of glycopeptide resistance in enterococci associated with transfer of vanB. Antimicrob. Agents Chemother 1997; 41: $872-874$.

7. Hayden MK, Trenholme GM, Schultz JE, Sahm DF. In vivo development of teicoplanin resistance in a VanB Enterococcus faecium isolate. $J$ Infect Dis 1993; 167: 1224-1227.

8. Green M, Binczewski B, Pasculle AW et al. Constitutively vancomycin-resistant Enterococcus faecium resistant to synergistic $\beta$-lactam combinations. Antimicrob Agents Chemother 1993; 37: $1238-1242$.

9. Sahm DF, Free L, Handwerger S. Inducible and constitutive expression of vanC-1-encoded resistance to vancomycin in Enterococcus gallinarum. Antimicrob Agents Chemother 1995; 39: $1480-1484$.

10. Arthur M, Molinas C, Depardieu F, Courvalin P. Characterization of $\operatorname{Tn} 1546$, a Tn3-related transposon conferring glycopeptide resistance by synthesis of depsipeptide peptidoglycan precursors in Enterococcus faecium BM4147. $J$ Bacteriol 1993; 175: 117-127.

11. Quintiliani R, Courvalin P. Characterization of $\operatorname{Tn} 1547$, a composite transposon flanked by IS16 and IS256-like elements, that confers vancomycin resistance in Enterococcus faecalis BM4281. Gene 1996. 172: 1-8.

12. Morrison D, Woodford N, Cookson B. Enterococci as emerging pathogens of humans. J Appl Microbiol 1997; 83 (Suppl): 89S-99S.

13. Brisson-Noel A, Dutka-Malen S, Molinas C, Leclercq R, Courvalin $\mathrm{P}$. Cloning and heterospecific expression of the resistance determinant vanA encoding high-level resistance to glycopeptides in Enterococcus faecium BM4147. Antimicrob Agents Chemother 1990; 34: 924-927.

14. Noble WC, Virani Z, Cree RGA. Co-transfer of vancomycin and other resistance genes from Enterococcus faecalis NCTC 12201 to Staphylococcus aureus. FEMS Microbiol Lett 1992; 93: $195-198$.

15. Fontana R, Ligozzi M, Pedrotti C, Padovani EM, Cornaglia G. 
Vancomycin-resistant Bacillus circulans carrying the vanA gene responsible for vancomycin resistance in enterococci. Eur J Clin Microbiol Infect Dis 1997; 16: 473-474.

16. Power EGM, Abdulla YH, Talsania HG, Spice W, Aathithan $\mathrm{S}$, French GL. vanA genes in vancomycin-resistant clinical isolates of Oeskovia turbata and Arcanobacterium (Corynebacterium) haemolyticum. J Antimicrob Chemother 1995; 36: 595-606.

17. Goldstein FW, Buu-Hoi AY, Williamson R, Acar JF. A vancomycin-resistant Enterococcus faecium susceptible to teichomycin. Program and Abstracts of the 27th Interscience Conference on Antimicrobial Agents and Chemotherapy 1987; 275. Abstract 1022 .

18. Williamson R, Al-Obeid S, Shlaes JH, Goldstein FW, Shlaes DM. Inducible resistance to vancomycin in Enterococcus faecium D366. J Infect Dis 1989; 159: 1095-1104.

19. Woodford N, Johnson AP, Morrison D, Chin ATL, Stephenson JR, George RC. Two distinct forms of vancomycin resistance amongst enterococci in the UK. Lancet 1990; 335: 226.

20. Quintiliani R, Evers S, Courvalin P. The vanB gene confers various levels of self-transferable resistance to vancomycin in enterococci. $J$ Infect Dis 1993; 167: 1220-1223.

21. Poyart C, Pierre C, Quesne G, Pron B, Berche P, Trieu-Cuot $P$. Emergence of vancomycin resistance in the genus Streptococcus: characterization of a vanB transferable determinant in Streptococcus bovis. Antimicrob Agents Chemother 1997; 41: 24-29.

22. Vincent S, Minkler P, Bincziewski B, Etter L, Shlaes DM Vancomycin resistance in Enterococcus gallinarum. Antimicrob Agents Chemother 1992; 36: 1392-1399.

23. Snell JJS, Brown DFJ, Perry SF, George R. Antimicrobial susceptibility testing of enterococci: results of a survey conducted by the United Kingdom National External Quality Assessment Scheme for Microbiology. I Antimicrob Chemother 1993; 32: 401-411.

24. Tenover FC, Tokars J, Swenson J, Paul S, Spitalny K, Jarvis W. Ability of clinical laboratories to detect antimicrobial agent-resistant enterococci. J Clin Microbiol 1993; 31: $1695-1699$

25. Jett B, Free L, Sahm DF. Factors influencing the Vitek grampositive susceptibility system's detection of vanB-encoded vancomycin resistance among enterococci. J Clin Microbio 1996; 34: $701-706$.

26. Rosenberg J, Tenover FC, Wong J, Jarvis W, Vugia DJ. Are clinical laboratories in California accurately reporting vancomycin-resistant enterococci? J Clin Microbiol 1997; 35 2526-2530.

27. Woodford N, Johnson AP, Morrison D, Speller DCE. Curren perspectives on glycopeptide resistance. Clin Microbiol Rev $1995 ; 8: 585-615$.

28. National Committee for Clinical Laboratory Standards. Methods for dilution antimicrobial susceptibility tests for bacteria that grow aerobically, 3rd edn. Approved Standard M7-A3 Villanova, PA, National Committee for Clinical Laboratory Standards. 1993.

29. Woodford N, Jones BL, Baccus Z, Ludlam HA, Brown DFJ Linkage of vancomycin and high-level gentamicin resistance genes on the same plasmid in a clinical isolate of Enterococcus faecalis. J Antimicrob Chemother 1995; 35 $179-184$

30. Woodford N, Morrison D, Johnson AP et al. Plasmidmediated vanB glycopeptide resistance in enterococci. Microb Drug Resist 1995; 1: 235-240.

31. Woodford N, Morrison D, Johnson AP, Briant V, George RC, Cookson B. Application of DNA probes for rRNA and vanA genes to investigation of a nosocomial cluster of vancomycinresistant enterococci. $J$ Clin Microbiol 1993; 31: 653-658.

32. Dutka-Malen S, Evers S, Courvalin P. Detection of glycopeptide resistance genotypes and identification to the species leve of clinically relevant enterococci by PCR. $J$ Clin Microbiol 1995; 33: 24-27.

33. Dutka-Malen S, Evers S, Courvalin P. Detection of glycopeptide resistance genotypes and identification to the species level of clinically relevant enterococci by PCR (Erratum). J Clin Microbiol 1995; 33: 1434.

34. Woodford N, Egelton CM, Morrison D. Comparison of PCR with phenotypic methods for the speciation of enterococci. In Horaud T, Bouvet A, Leclercq R, de Montclos H Sicard M (eds) Streptococci and the host. (Advances in experimental medicine and biology, vol 418.) New York; Plenum Publishing Corporation. 1997: 405-408.

35. Allen NE, Hobbs JN, Richardson JM, Riggin RM. Biosynthesis of modified peptidoglycan precursors by vancomycinresistant Enterococcus faecium. FEMS Microbiol Lett 1992; 98: $109-115$.

36. Arthur M, Molinas C, Bugg TDH, Wright GD, Walsh CT, Courvalin P. Evidence for in vivo incorporation of D-lactate into peptidoglycan precursors of vancomycin-resistant enterococci. Antimicrob Agents Chemother 1992; 36: 867-869.

37. Handwerger S, Pucci MJ, Volk KJ, Liu J, Lee MS. The cytoplasmic peptidoglycan precursor of vancomycin-resistant Enterococcus faecalis terminates in lactate. J Bacteriol 1992 174: $5982-5984$

38. Billot-Klein D, Shlaes D, Bryant D, Bell D, van Heijenoort J Gutmann L. Peptidoglycan structure of Enterococcus faecium expressing vancomycin resistance of the VanB type. Biochem $J$ 1996; 313: 711-715.

39. Reynolds PE, Snaith HA, Maguire AJ, Dutka-Malen S, Courvalin P. Analysis of peptidoglycan precursors in vancomycin-resistant Enterococcus gallinarum BM4174. Biochem $J$ 1994; 301: 5-8.

40. Bugg TDH, Dutka-Malen S, Arthur M, Courvalin P, Walsh CT. Identification of vancomycin resistance protein VanA as a D-alanine:D-alanine ligase of altered substrate specificity. Biochemistry 1991; 30: 2017-2021.

41. Evers S, Reynolds PE, Courvalin P. Sequence of the vanB and $d d l$ genes encoding D-alanine:D-lactate and D-alanine:Dalanine ligases in vancomycin-resistant Enterococcus faecalis V583. Gene 1994; 140: 97-102.

42. Evers S, Sahm DF, Courvalin P. The vanB gene of vancomycin-resistant Enterococcus faecalis V583 is structurally related to genes encoding D-Ala:D-Ala ligases and glycopeptide-resistance proteins VanA and VanC. Gene $1993 ; 124: 143-144$

43. Dutka-Malen S, Molinas C, Arthur M, Courvalin P. Sequence of the vanC gene of Enterococcus gallinarum BM4174 encoding a D-alanine:D-alanine ligase-related protein necessary for vancomycin resistance. Gene 1992; 112: 53-58.

44. Navarro F, Courvalin P. Analysis of genes encoding Dalanine:D-alanine ligase-related enzymes in Enterococcus casseliflavis and Enterococcus flavescens. Antimicrob Agents Chemother 1994; 38: 1788-1793.

45. Uttley AHC, George RC, Naidoo J et al. High-level vancomycin-resistant enterococci causing hospital infection. Epidemiol Infect 1989; 103: 173-181.

46. Handwerger S, Skoble J. Identification of chromosomal mobile element conferring high-level vancomycin resistance in Enterococcus faecium. Antimicrob Agents Chemother 1995. 39: $2446-2453$.

47. Quintiliani R, Courvalin P. Conjugal transfer of the vancomycin resistance determinant vanB between enterococci involves the movement of large genetic elements from chromosome to chromosome. FEMS Microbiol Lett 1994; 119: $359-364$.

48. Arthur M, Molinas C, Dutka-Malen S, Courvalin P. Structura relationship between the vancomycin resistance protein $\mathrm{VanH}$ and 2-hydroxycarboxylic acid dehydrogenases. Gene 1991; 103: $133-134$.

49. Bugg TDH, Wright GD, Dutka-Malen S, Arthur M, Courvalin $\mathrm{P}$, Walsh CT. Molecular basis for vancomycin resistance in Enterococcus faecium BM4147: biosynthesis of a depsipeptide peptidoglycan precursor by vancomycin resistance proteins VanH and VanA. Biochemistry 1991; 30: 10408-10415.

50. Evers S, Courvalin P. Regulation of VanB-type vancomycin resistance gene expression by the $\operatorname{VanS}_{\mathrm{B}}-\operatorname{VanR}_{\mathrm{B}}$ two-component regulatory system in Enterococcus faecalis V583. $J$ Bacteriol 1996; 178: 1302-1309.

51. Reynolds PE, Depardieu F, Dutka-Malen S, Arthur M, Courvalin P. Glycopeptide resistance mediated by enterococcal transposon $\mathrm{Tn} 1546$ requires production of VanX for hydrolysis of D-alanyl-D-alanine. Mol Microbiol 1994; 13: 1065-1070.

52. Wright GD, Molinas C, Arthur M, Courvalin P, Walsh CT Characterization of VanY, a DD-carboxypeptidase from vancomycin-resistant Enterococcus faecium BM4147. Antimicrob Agents Chemother 1992; 36: 1514-1518.

53. Arthur M, Depardieu F, Snaith HA, Reynolds PE, Courvalin P. Contribution of VanY D,D-carboxypeptidase to glycopeptide resistance in Enterococcus faecalis by hydrolysis of peptido- 
glycan precursors. Antimicrob Agents Chemother 1994; 38: 1899-1903.

54. Arthur M, Depardieu F, Molinas C, Reynolds P, Courvalin P. The vanZ gene of $\operatorname{Tn} 1546$ from Enterococcus faecium BM4147 confers resistance to teicoplanin. Gene 1995; 154: $87-92$.

55. Nicas TI, Wu CYE, Hobbs JN, Preston DA, Allen NE. Characterization of vancomycin resistance in Enterococcus faecium and Enterococcus faecalis. Antimicrob Agents Chemother 1989; 33: 1121-1124.

56. Shlaes DM, Bouvet A, Devine C, Shlaes JH, al-Obeid S, Williamson R. Inducible, transferable resistance to vancomycin in Enterococcus faecalis A256. Antimicrob Agents Chemother 1989; 33: 198-203.

57. Arthur M, Molinas C, Courvalin P. The VanS-VanR twocomponent regulatory system controls synthesis of depsipeptide peptidoglycan precursors in Enterococcus faecium BM4147. J Bacteriol 1992; 174: 2582-2591.

58. Holman TR, Wu Z, Wanner BL, Walsh CT. Identification of the DNA-binding site for the phosphorylated VanR protein required for vancomycin resistance in Enterococcus faecium. Biochemistry 1994; 33: 4625-4631.

59. Arthur M, Depardieu F, Gerbaud G, Galimand M, Leclercq R, Courvalin $P$. The VanS sensor negatively controls VanRmediated transcriptional activation of glycopeptide resistance genes in $\operatorname{Tn} 1546$ and related elements in the absence of induction. $J$ Bacteriol 1997; 179: 97-106.

60. Handwerger S, Discotto L, Thanassi J, Pucci MJ. Insertional inactivation of a gene which controls expression of vancomycin resistance on plasmid pHKK100. FEMS Microbiol Lett 1992; 92: 11-14.

61. Baptista M, Depardieu F, Reynolds P, Courvalin P, Arthur M. Mutations leading to increased levels of resistance to glycopeptide antibiotics in VanB-type enterococci. Mol Microbiol 1997; 25: 93-105.

62. Fraimow HS, Jungkind DL, Lander DW, Delso DR, Dean JL. Urinary tract infection with an Enterococcus faecalis isolate that requires vancomycin for growth. Ann Intern Med 1994; 121: $22-26$.

63. Woodford N, Johnson AP, Morrison D et al. Vancomycindependent enterococci in the United Kingdom. $J$ Antimicrob Chemother 1994; 33: 1066.

64. Green M, Shlaes JH, Barbadora K, Shlaes DM. Bacteremia due to vancomycin-dependent Enterococcus faecium. Clin Infect Dis 1995; 20: 712-714.

65. Slifkin M, Weinbaum D, Cumbie R. Vancomycin-dependent Enterococcus faecium from a blood culture. Med Microbiol Lett 1995; 4: 406-413.

66. Wilks M; Farrag N, Eltringham IJ; Hayek L; Rossney AS, McConkey SJ, Keane CT. Vancomycin-dependent enterococcus. Lancet 1997; 349: 429-430 (four letters)

67. Stewart B, Hall L, Duke B, Ball D. Vancomycin-dependent enterococci: curious phenomenon or serious threat? $J$ Antimicrob Chemother 1997; 40: 734-735.

68. Rosato A, Pierre J, Billot-Klein D, Buu-Hoi A, Gutmann L. Inducible and constitutive expression of resistance to glycopeptides and vancomycin dependence in glycopeptide-resistant Enterococcus avium. Antimicrob Agents Chemother 1995; 39: $830-833$.

69. Aslangul E, Baptista M, Fantin B et al. Selection of glycopeptide-resistant mutants of Van-B-type Enterococcus faecalis BM4281 in vitro and in experimental endocarditis. $J$ Infect Dis 1997; 175: 598-605.

70. Sifaoui F, Gutmann L. Vancomycin dependence in a VanAproducing Enterococcus avium strain with a nonsense mutation in the natural D-Ala-D-Ala ligase gene. Antimicrob Agents Chemother 1997; 41: 1409.

71. Farrag N, Eltringham I, Liddy H. Vancomycin-dependent Enterococcus faecalis. Lancet 1996; 348: 1581-1582.

72. Jett BD, Huycke MM, Gilmore MS. Virulence in enterococci. Clin Microbiol Rev 1994; 7: 462-478.

73. Johnson AP. The pathogenicity of enterococci. J Antimicrob Chemother 1994; 33: 1083-1089.

74. Morrison D, Woodford N, Cookson BD. Epidemic vancomycin-resistant Enterococcus faecium in the UK. Clin Microbiol Infect 1996; 1: 146-147.

75. Morrison D, Cooke RPD, Kaufmann ME, Cookson BD, Stephenson J. Inter-hospital spread of vancomycin-resistant Enterococcus faecium. J Hosp Infect 1997; 36: 77-78.
76. Chadwick PR, Oppenheim BA, Fox A, Woodford N, Morgenstern GR, Scarffe JH. Epidemiology of an outbreak due to glycopeptide-resistant Enterococcus faecium on a leukaemia unit. J Hosp Infect 1996; 34: 171-182.

77. Johnson AP, Uttley AHC, Woodford N, George RC. Resistance to vancomycin and teicoplanin: an emerging clinical problem. Clin Microbiol Rev 1990; 3: 280-291.

78. McDonald LC, Jarvis WR. The global impact of vancomycinresistant enterococci. Curr Opin Infect Dis 1997; 10: 304-309.

79. Chow JW, Kuritza A, Shlaes DM, Green M, Sahm DF, Zervos MJ. Clonal spread of vancomycin-resistant Enterococcus faecium between patients in three hospitals in two states. J Clin Microbiol 1993; 31: 1609-1611.

80. Dunne WM, Wang W. Clonal dissemination and colony morphotype variation of vancomycin-resistant Enterococcus faecium isolates in Metropolitan Detroit, Michigan. $J$ Clin Microbiol 1997; 35: 388-392.

81. Bates J, Jordens Z, Selkon JB. Evidence for an animal origin of vancomycin-resistant enterococci. Lancet 1993; 342: $490-491$.

82. Bates J, Jordens JZ, Griffiths DT. Farm animals as a putative reservoir for vancomycin-resistant enterococcal infection in man. J Antimicrob Chemother 1994; 34: 507-514.

83. Torres C, Reguera JA, Sanmartin MJ, Perez-Diaz JC, Baquero F. vanA-Mediated vancomycin-resistant Enterococcus spp. in sewage. J Antimicrob Chemother 1994; 33: 553-561.

84. Aarestrup FM. Occurrence of glycopeptide resistance among Enterococcus faecium isolates from conventional and ecological poultry farms. Microb Drug Resist 1995; 1: 255-257.

85. Klare I, Heier H, Claus $\mathrm{H}$ et al. Enterococcus faecium strains with vanA-mediated high-level glycopeptide resistance isolated from animal foodstuffs and fecal samples of humans in the community. Microb Drug Resist 1995; 1: 265-272.

86. Klare I, Heier $\mathrm{H}$, Claus $\mathrm{H}$, Reissbrodt $\mathrm{R}$, Witte W. vanAmediated high-level glycopeptide resistance in Enterococcus faecium from animal husbandry. FEMS Microbiol Lett 1995; 125: $165-172$.

87. Witte W, Klare I. Glycopeptide-resistant Enterococcus faecium outside hospitals: a commentary. Microb Drug Resist 1995; 1: 259-263.

88. Aarestrup FM, Ahrens P, Madsen M, Pallesen LV, Poulsen RL, Westh H. Glycopeptide susceptibility among Danish Enterococcus faecium and Enterococcus faecalis isolates of animal and human origin and PCR identification of genes within the VanA cluster. Antimicrob Agents Chemother 1996; 40: 1938-1940.

89. Chadwick PR, Woodford N, Kaczmarski EB, Gray S, Barrell RA, Oppenheim BA. Glycopeptide-resistant enterococci from uncooked meat. J Antimicrob Chemother 1996; 38: 908-909.

90. Devriese LA, Ieven M, Goossens $\mathrm{H}$ et al. Presence of vancomycin-resistant enterococci in farm and pet animals. Antimicrob Agents Chemother 1996; 40: 2285-2287.

91. Van der Auwera P, Pensart N, Korten V, Murray BE, Leclerce R. Influence of oral glycopeptides on the fecal flora of human volunteers: selection of highly glycopeptide-resistant enterococci. J Infect Dis 1996; 173: 1129-1136.

92. Wegener HC, Madsen M, Nielsen N, Aarestrup FM. Isolation of vancomycin resistant Enterococcus faecium from food. Int J Food Microbiol 1997; 35: 57-66.

93. Coque TM, Tomayko JF, Ricke SC, Okhyusen PC, Murray BE. Vancomycin-resistant enterococci from nosocomial, community, and animal sources in the United States. Antimicrob Agents Chemother 1996; 40: 2605-2609.

94. Dunne WMJ, Dunne BS, Smith D. Watch out where the huskies go. ASM News 1996; 62: 283.

95. Schouten MA, Voss A, Hoogkamp-Korstanje JAA. VRE and meat. Lancet 1997; 349: 1258.

96. van Belkum A, van den Braak N, Thomassen R, Verbrugh $\mathrm{H}$, Endtz $\mathrm{H}$. Vancomycin-resistant enterococci in cats and dogs. Lancet 1996; 348: 1038-1039.

97. Wise R. Avoparcin and animal feedstuff. Lancet 1996; 347: 1835 .

98. Mudd A. Vancomycin resistance and avoparcin. Lancet 1996; 347: 1412 .

99. Bager F, Madsen M, Christensen J, Aarestrup FM. Avoparcin used as a growth promoter is associated with the occurrence of vancomycin-resistant Enterococcus faecium on Danish poultry and pig farms. Prev Vet Med 1997; 31: 95-112. 
100. McDonald LC, Kuehnert MJ, Tenover FC, Jarvis WR Vancomycin-resistant enterococci outside the health-care setting: prevalence, sources, and public health implications. Emerg Infect Dis 1997; 3: 311-317.

101. van den Bogaard AE, Jensen LB, Stobberingh EE. Vancomycin-resistant enterococci in turkeys and farmers. $N \mathrm{Engl} \mathrm{J}$ Med 1997; 337: 1558-1559.

102. Miele A, Bandera M, Goldstein BP. Use of primers selective for vancomycin resistance genes to determine van genotype in enterococci and to study gene organization in VanA isolates. Antimicrob Agents Chemother 1995; 39: 1772-1778.

103. Jensen LB, Ahrens P, Dons L, Jones RN, Hammerum AM, Aarestrup FM. Molecular analysis of Tn1546 in Enterococcus faecium isolated from animals and humans. $J$ Clin Microbiol 1998 (in press).

104. Woodford N, Adebiyi AA, Palepou MI, Cookson BD. Diversity of VanA glycopeptide resistance elements in enterococci from human and non-human sources. Antimicrob Agents Chemother 1998; 42: 502-508.

105. Handwerger S, Skoble J, Discotto LF, Pucci MJ. Heterogeneity of the vanA gene cluster in clinical isolates of enterococci from the Northeastern United States. Antimicrob Agents Chemother 1995; 39: 362-368.

106. Mackinnon MG, Drebot MA, Tyrell GJ. Identification and characterization of IS1476, an insertion sequence-like element that disrupts VanY function in a vancomycin-resistant Enterococcus faecium strain. Antimicrob Agents Chemother 1997; 41: 1805-1807.

107. Woodford N, Watson AP, Chadwick PR. Investigation by long PCR of the genetic elements mediating VanA glycopeptide resistance in enterococci from uncooked meat in South Manchester. In: Horaud T, Bouvet A, Leclercq R, de Montclos H, Sicar M. (eds) Streptococci and the host. Plenum, (Advances in experimental medicine and biology, vol 418.) New York. 1997: 409-412.

108. Woodford N, Stigter JM. Molecular investigation of glycopeptide resistance in gram-positive bacteria. In: Woodford N, Johnson AP (eds) Molecular bacteriology: protocols and clinical applications. Humana Press, Totowa, NJ. 1998: 579-615.

109. Dutka-Malen S, Molinas C, Arthur M, Courvalin P. The VANA glycopeptide resistance protein is related to D-alanyl-Dalanine ligase cell wall biosynthesis enzymes. Mol Gen Genet 1990; 224: 364-372.

110. Dutka-Malen S, Leclercq R, Coutant V, Duval J, Courvalin P Phenotypic and genotypic heterogeneity of glycopeptide resistance determinants in gram-positive bacteria. Antimicrob Agents Chemother 1990; 34: 1875-1879.

111. Sosio M, Lorenzetti R, Robbiati F, Denaro M. Nucleotide sequence to a teicoplanin resistance gene from Actinoplanes teichomyceticus. Biochem Biophys Acta 1991; 1089: 401-403.

112. Billot-Klein D, Gutmann L, Sable S, Guittet E, van Heijenoor $\mathrm{J}$. Modification of peptidoglycan precursors is a common feature of the low-level vancomycin-resistant VANB-type
Enterococcus faecium D366 and of the naturally glycopeptide-resistant species Lactobacillus casei, Pediococcus pentosaceus, Leuconostoc mesenteroides, and Enterococcus gallinarum. J Bacteriol 1994; 176: 2398-2405.

113. Elisha BG, Courvalin P. Analysis of genes encoding Dalanine:D-alanine ligase-related enzymes in Leuconostoc mesenteroides and Lactobacillus spp. Gene 1995; 152: 79-83.

114. Handwerger S, Pucci MJ, Volk KJ, Liu J, Lee MS Vancomycin-resistant Leuconostoc mesenteroides and Lactobacillus casei synthesize cytoplasmic peptidoglycan precursors that terminate in lactate. $J$ Bacteriol $1994 ; 176$ : 260-264.

115. Evers S, Casadewall B, Charles M, Dutka-Malen S, Galimand $M$, Courvalin P. Evolution of structure and substrate specificity in D-alanine:D-alanine ligases and related enzymes. J Mol Evol 1996; 42: 706-712.

116. Marshall CG, Broadhead G, Leskiw BK, Wright GD. D-AlaD-ala ligases from glycopeptide antibiotic-producing organisms are highly homologous to the enterococcal vancomycinresistance ligases VanA and VanB. Proc Natl Acad Sci USA 1997; 94: 6480-6483.

117. Moellering RC. The enterococcus: a classic example of the impact of antimicrobial resistance on therapeutic options. $J$ Antimicrob Chemother 1991; 28: 1-12.

118. Murray BE. The life and times of the Enterococcus. Clin Microbiol Rev 1990; 3: 46-65.

119. Michel M, Gutmann L. Methicillin-resistant Staphylococcus aureus and vancomycin-resistant enterococci: therapeutic realities and possibilities. Lancet 1997; 349: 1901-1906.

120. Fantin B, Leclercq R, Arthur M, Duval J, Carbon C. Influence of low-level resistance to vancomycin on efficacy of teicoplanin and vancomycin for treatment of experimental endocarditis due to Enterococcus faecium. Antimicrob Agents Chemother 1991; 35: 1570-1575.

121. Nicas TI, Zeckel ML, Braun DK. Beyond vancomycin: new therapies to meet the challenge of glycopeptide resistance. Trends Microbiol 1997; 5: 240-249.

122. Woodford N, Palepou M-F, Johnson AP, Chadwick PR, Bates J. Methicillin-resistant Staphylococcus aureus and vancomycin-resistant enterococci. Lancet 1997; 350: 738.

123. Hiramatsu K, Hanaki H, Ino T, Yabuta K, Oguri T, Tenove FC. Methicillin-resistant Staphylococcus aureus clinical strain with reduced vancomycin susceptibility. $J$ Antimicrob Chemother 1997; 40: 135-136.

124. Martin R, Wilcox KR. Staphylococcus aureus with reduced susceptibility to vancomycin - United States, 1997. MMWR 1997; 46: 765-766.

125. Anonymous. Detecting vancomycin intermediate Staphylococcus aureus. CDR Weekly 1997; 7: 417-420.

126. Boyle-Vavra S, de Jonge BLM, Ebert CC, Daum RS. Cloning of the Staphylococcus aureus ddh gene encoding NAD+dependent D-lactate dehydrogenase and insertional inactivation in a glycopeptide-resistant isolate. $J$ Bacteriol 1997; 179: $6756-6763$ 